\title{
Community-associated Methicillin-resistant Staphylococcus aureus Bacteremia and Endocarditis among HIV Patients: A cohort study
}

\author{
Jon P Furuno ${ }^{1,5}$, Jennifer K Johnson², Marin L Schweizer ${ }^{3}$, Anayochukwu Uche ${ }^{4}$, Oscar C Stine ${ }^{5}$,
} Simone M Shurland ${ }^{5,6}$ and Graeme N Forrest ${ }^{7 *}$

\begin{abstract}
Background: HIV patients are at increased risk of development of infections and infection-associated poor health outcomes. We aimed to 1) assess the prevalence of USA300 community-associated methicillin-resistant Staphylococcus aureus (CA-MRSA) among HIV-infected patients with S. aureus bloodstream infections and. 2) determine risk factors for infective endocarditis and in-hospital mortality among patients in this population.

Methods: All adult HIV-infected patients with documented S. aureus bacteremia admitted to the University of Maryland Medical Center between January 1, 2003 and December 31, 2005 were included. CA-MRSA was defined as a USA300 MRSA isolate with the MBQBLO spa-type motif and positive for both the arginine catabolic mobile element and Panton-Valentin Leukocidin. Risk factors for S. aureus-associated infective endocarditis and mortality were determined using logistic regression to calculate odds ratios (OR) and 95\% confidence intervals (Cl). Potential risk factors included demographic variables, comorbid illnesses, and intravenous drug use.

Results: Among 131 episodes of S. aureus bacteremia, 85 (66\%) were MRSA of which 47 (54\%) were CA-MRSA. Sixty-three patients (48\%) developed endocarditis and 10 patients (8\%) died in the hospital on the index admission Patients with CA-MRSA were significantly more likely to develop endocarditis $(\mathrm{OR}=2.73,95 \% \mathrm{Cl}=1.30,5.71)$. No other variables including comorbid conditions, current receipt of antiretroviral therapy, pre-culture severity of illness, or CD4 count were significantly associated with endocarditis and none were associated with in-hospital mortality.

Conclusions: CA-MRSA was significantly associated with an increased incidence of endocarditis in this cohort of HIV patients with MRSA bacteremia. In populations such as these, in which the prevalence of intravenous drug use and probability of endocarditis are both high, efforts must be made for early detection, which may improve treatment outcomes.
\end{abstract}

\section{Background}

Staphylococcus aureus bacteremia is a serious health condition associated with considerable morbidity and mortality among infected patients [1]. Negative outcomes associated with $S$. aureus bacteremia include prolonged hospital stay, endocarditis, sepsis, and death $[1,2]$. The changing epidemiology of S. aureus, including the increasing incidence and prevalence of methicillin-

\footnotetext{
* Correspondence: forrestg@ohsu.edu

${ }^{7}$ Division of Infectious Diseases, Portland VA Medical Center and Oregon Health Science University, Portland, OR, USA

Full list of author information is available at the end of the article
}

resistant S. aureus (MRSA) and the emergence of community-associated MRSA (CA-MRSA) further challenges clinicians when treating $S$. aureus bacteremia. A recent meta-analysis suggested that patients with MRSA bacteremia are at increased risk of death, and a longer post infection hospital length of stay compared to patients with bacteremia due to methicillin-susceptible $S$. aureus [1]. Furthermore, increasing evidence suggests that transmission of CA-MRSA is becoming more prevalent in healthcare settings and an emerging epidemic throughout the HIV community $[3,4]$.

\section{Biomed Central}

(c) 2011 Furuno et al; licensee BioMed Central Ltd. This is an Open Access article distributed under the terms of the Creative Commons Attribution License (http://creativecommons.org/licenses/by/2.0), which permits unrestricted use, distribution, and reproduction in any medium, provided the original work is properly cited. 
Decreased host immunity among HIV-infected patients places them at increased risk of infection including $S$. aureus bacteremia and associated poor outcomes $[3,5,6]$. Studies suggest that HIV patients are also at increased risk of CA-MRSA infections from overlapping community networks as well as the high prevalence of intravenous drug use in some areas $[7,8]$. Independent factors described as risks for MRSA bacteremia within HIV-infected patients have been intravenous drug use, hemodialysis and CD4 counts < 200 [9] while clinical outcomes suggest that incidence of re-infection and one-year mortality are high [3]. Recent data from a study by Kempker et al. suggested that CA-MRSA bacteremia was associated with advanced age, black race and AIDS infection as well as increased mortality compared to other strains [10]. However, despite this recent work, outcomes for CA-MRSA bacteremia and endocarditis among HIV patients have not been well-described. In this study we aimed to 1) assess the prevalence of USA300 community-associated methicillin-resistant Staphylococcus aureus (CA-MRSA) among HIV-infected patients with $S$. aureus bloodstream infections and 2) determine risk factors for infective endocarditis and inhospital mortality among patients in this population.

\section{Methods}

\section{Study Population}

Prior to study commencement, the University of Maryland, Baltimore Institutional Review Board approved this study. This was a retrospective cohort study of all adult (age $\geq 18$ ) HIV-infected patients with MRSA bacteremia admitted to the University of Maryland Medical Center (UMMC) between January 1, 2003 and December 31, 2005. During the study period, UMMC was a 648-bed, tertiary-care facility in Baltimore, MD, which included a 40-bed in-patient HIV service. Baltimore has the fifth highest incidence case report rate of people living with HIV/AIDS of any major metropolitan area in the U.S. with 2037.8 cases/100,000 population as of 2007and a high incidence of CA-MRSA at approximately 119 cases/100,000 population [11,12]. Data on rates of MRSA infection admitted to UMMC within this time period of being consistently around $50 \%$ have previously been published [13].

Patients with MRSA bacteremia for the time period evaluated were identified through Premier Safety Surveillor $^{\circledR}$ (Premier, Inc., Charlotte, N.C), an automated epidemiological surveillance program used by UMMC for infection control purposes and from which work has previously been described [14,15]. Duplicate cultures from the same admission were then removed and HIV status was then cross-referenced with the central data repository. The central data repository has been used in numerous epidemiologic studies of antimicrobial- resistant bacteria published in the peer-reviewed journals [16-18]. The flow diagram shows how the final patient population was determined. (Figure 1)

\section{Data Collection}

Patient data were retrospectively collected via review of patient medical charts and through a central data repository of patients' administrative, pharmaceutical, and laboratory data. Chart review was performed by a clinician using a standardized data abstraction form. Data collected included past and current medical history: demographics, comorbid conditions, and clinical presentation on admission and just prior to positive blood culture. Clinical presentation included CD4 count (cells/ $\mathrm{mm}^{3}$ ), and whether the patient was receiving effective antiretroviral therapy (ART) of at least 3 active agents. In addition, data on HIV viral load were collected if available within 6 weeks (on either side) of the admission.

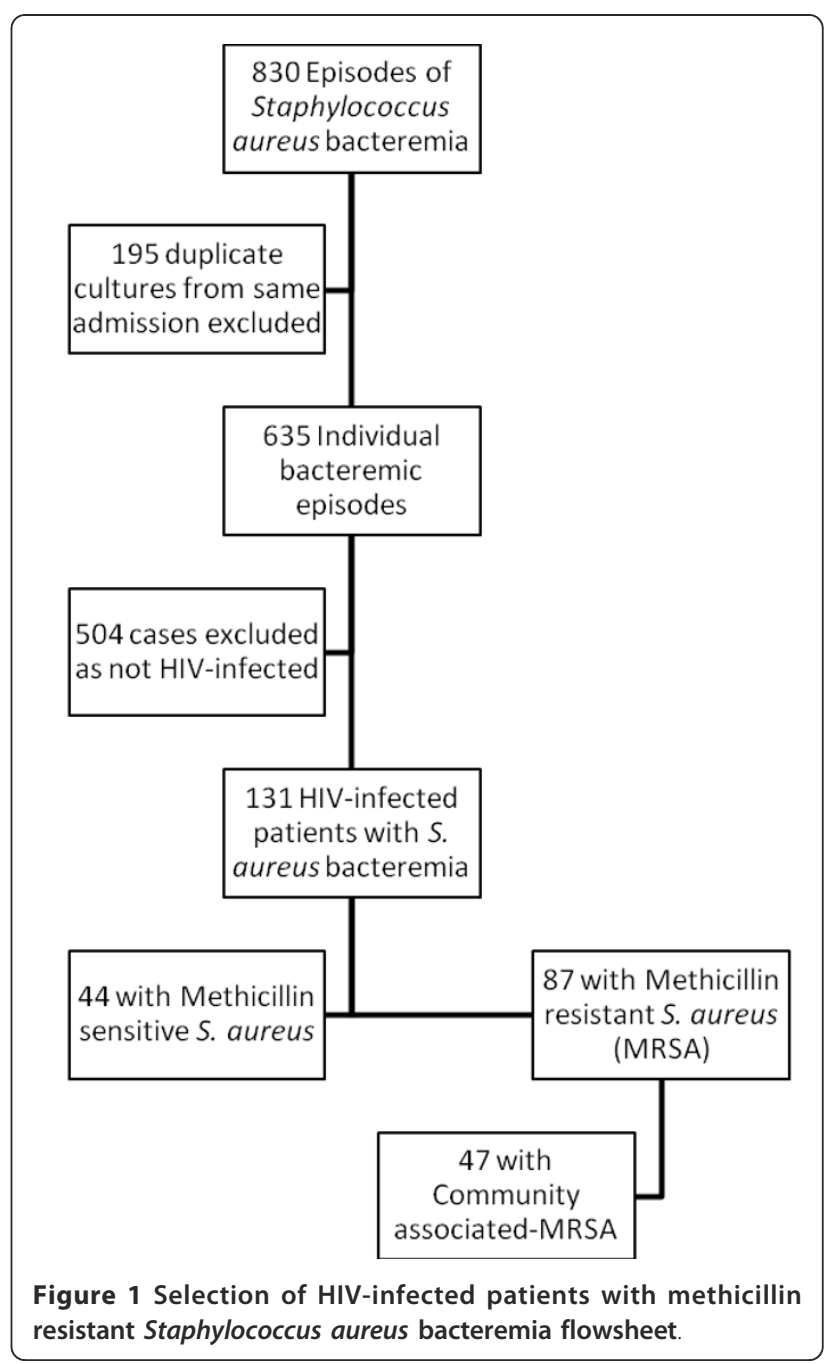




\section{Variable Definitions}

AIDS was defined as a CD $4<200$ cells $/ \mathrm{mm}^{3}$ or current opportunistic infection, Hepatitis $\mathrm{C}$ infection was defined as having documented serologic positivity, diabetes mellitus was defined as receiving insulin or oral hypoglycemic medication, hypertension was any patient receiving antihypertensive therapy, coronary artery disease was defined as any prior myocardial infarction, interventional procedure or bypass surgery. Illicit substance use (ISU) was determined by history and when possible toxicology screen results. End stage renal disease was defined as per National Kidney Foundation guidelines as stage 4 or 5 kidney disease including the need for renal replacement therapy [19]. Severity of illness was defined using the Acute Physiology and Chronic Health Evaluation (APACHE) II score at the time of initial positive blood culture collection. Endocarditis was diagnosed using either transesophageal (TEE) or transthoracic echocardiography (TTE) and defined according to the modified Duke criteria, with allocation to left-sided, right-sided, or bilateral disease [20]. Mortality was defined as in-hospital mortality on the index admission.

\section{Laboratory Methods}

Blood cultures were drawn as per standard hospital policy from two separate sites and collected in blood culture bottles (BacTAlert, bioMerieux, Durham, NC). Cultures were placed in a continuous automated detection incubator. Positive blood culture bottles were plated onto standard growth media as per standard laboratory protocol and susceptibilities were performed using disk diffusion following the Clinical and Laboratory Standards Institute (CLSI) guidelines [21,22]. The first $S$. aureus positive blood culture per patient per admission was included in the analysis. Thus, patients could have contributed more than one episode of $S$. aureus bacteremia to the data, so long as the cultures occurred on different inpatient admissions and were not treated for endocarditis in last 90 days.

MRSA spa-type was determined using the methods proposed by Shopsin et al. and Harmsen et al [23,24]. Presence of Panton-Valentine leukocidin (PVL) and arginine catabolic mobile element (ACME) was determined using the previously described protocols $[25,26]$. CA-MRSA was defined as a USA300 MRSA isolate with the MBQBLO spa-type motif that was both PVL and ACME positive as has been previously described $[25,27,28]$. This method was validated by performing pulsed-field gel electrophoresis on isolates that met two of the three following criteria: MBQBLO spa-type motif, PVL positive, ACME positive. Of those that met two of the three criteria, none were USA300. Although there are other CA-MRSA strains, USA300 MRSA is the predominant strain type associated with CA-MRSA colonization and infection [29].

\section{Statistical analysis}

Student's t-tests, chi-square, Fisher's exact, and Wilcoxon rank sum tests were used to identify differences between patients with an without CA-MRSA and between those who and did and did not develop endocarditis or die on the index admission. All variables that were statistically significant $(\alpha=0.1)$ in the bivariable analyses were included in the initial (full) multivariable logistic regression model. In each of the multivariable analyses performed, variables not significantly associated ( $\alpha=0.05$ ) with the outcome were removed from the model. Each of the removed variables was then reinserted into the model to assess if its presence altered the regression coefficient by $20 \%$ or more. If so, this confounding variable was included in the final model. The resulting multivariable logistic regression model was considered the final model and was used to calculate odds ratios (ORs) and 95\% confidence intervals (CI) for the remaining risk factors. All analyses were conducted using SAS statistical software, Version 9.1.2 (SAS Institute, Cary, NC).

\section{Results}

We identified 131 individual episodes of S. aureus bacteremia among HIV-positive patients during the study period. All episodes occurred within 72 hours of admission. Characteristics of the study population are displayed in Table 1.Twenty one percent of the patients had a diagnosis of AIDS. The mean CD4 count of the cohort was 126 cells/per $\mathrm{mm}^{3}$ (standard deviation $=133$ cells/per $\mathrm{mm}^{3}$ ) and median CD4 count was 56 cells/per $\mathrm{mm}^{3}$ (interquartile range [IQR] 16-169 cells/per $\mathrm{mm}^{3}$ ). The mean HIV viral load was 225,000 copies/ml and only 15 patients having a suppressed HIV viral load in this cohort. Of note, prevalence of co-infection with hepatitis $C$ virus was $63 \%$, prevalence of ISU was $50 \%$, and $30 \%$ of patients were receiving ART. Approximately $66 \%(\mathrm{n}=87)$ of $S$. aureus isolates were MRSA of which 47 (54\%) were CA-MRSA. Antibiotic susceptibilities and molecular characteristics of the $S$. aureus isolates are displayed in Table 2. Initial empiric antibiotic selection for the treatment of CA-MRSA bacteremia would not be effective therapy in 27 of the patients (31\%).

The prevalence of endocarditis was approximately $48 \%$ and in-hospital mortality during the index admission was approximately $8 \%$. Among the 63 patients with endocarditis, 51 (81\%) had right-sided endocarditis only. Of the 31 MRSA patients (35\%) that had both a TEE and TTE, 5 vegetations ( 2 aortic, 2 mitral, 1 pulmonic) were detected by TEE that were not seen by TTE, but this was not related to whether they had CA or Non- 
Table 1 Characteristics of the Patients with Staphylococcus aureus bacteremia $(n=131)$

\begin{tabular}{lc}
\hline Characteristic & $\mathbf{n}(\%)$ \\
\hline Mean (SD) Age, (years) & $41.5(7.5)$ \\
\hline Male Sex & $83(63.4)$ \\
\hline African American & $119(91)$ \\
\hline Receiving ART & $39(29.8)$ \\
\hline Mean (SD) APACHE Score & $12.1(5.3)$ \\
\hline CD4 <200 cells/mm ${ }^{3}$ & $28(21.4)$ \\
\hline Hepatitis C & $82(62.6)$ \\
\hline Diabetes Mellitus & $3(2.3)$ \\
\hline Coronary Artery Disease & $0(-)$ \\
\hline Hypertension & $13(9.9)$ \\
\hline Intravenous Drug Use & $66(50.4)$ \\
\hline End-stage Renal Disease & $24(18.3)$ \\
\hline Median (IQR) Length of Stay (days) & $7(5,14)$ \\
\hline Endocarditis & $63(48.1)$ \\
\hline \multicolumn{1}{c}{ Right-sided only } & $51(38.9)$ \\
\hline Left-sided only & $8(6.1)$ \\
\hline Bilateral & $4(3.1)$ \\
\hline In-hospital Mortality & $10(7.6)$ \\
\hline
\end{tabular}

Note: ART: Antiretroviral therapy, SD: standard deviation, IQR: interquartile range, APACHE: Acute Physiology and Chronic Health Evaluation score.

CA-MRSA infection. Metastatic MRSA infections were common with septic pulmonary emboli occurring in 11 of the CA-MRSA patients and 6 non-CA-MRSA patients $(p=0.32)$. However, there were significantly more deep abscesses in the CA-MRSA group compared to the non-CA-MRSA group (17 versus $1 \mathrm{p}<0.001)$. Of the 17 CA-MRSA patients with deep abscesses, 7 patients had lung abscess or empyema, 5 patients had pyomyositis (psoas and spinal muscle abscesses), 2 patients had renal abscesses, 2 patients had a brain abscess and one patient had a pericardial empyema. The non-CA-MRSA group deep abscesses had one epidural abscess. The mean duration of bacteremia was not significantly different between the patients with CA-MRSA

Table 2 Characteristics of the Staphylococcus aureus isolates $(n=131)$

\begin{tabular}{|c|c|}
\hline Characteristic & n (\%) \\
\hline \multicolumn{2}{|l|}{ Antibiotic Susceptibilities } \\
\hline Methicillin Resistant & $87(66)$ \\
\hline Clindamycin Resistant & $25(19.1)$ \\
\hline Trimethoprim-Sulfamethoxazole Resistant & $42(32.1)$ \\
\hline \multicolumn{2}{|l|}{ Molecular Characteristics* } \\
\hline Panton Valentine Leukocidin (PVL)* & $53(61.6)$ \\
\hline Arginine Catabolic Mobile Element (ACME)* & $50(58.1)$ \\
\hline USA300 MRSA* & $47(54.0)$ \\
\hline
\end{tabular}

*Proportion is only among MRSA isolates (mean 1.85 days) and those with non-CA-MRSA (1.45 days) $\mathrm{p}=0.43$ ).

Table 3 displays the unadjusted odds ratios for the association between different variables and endocarditis. Patients with CA-MRSA infections had nearly three times the odds of endocarditis and this association was statistically significant $(\mathrm{OR}=2.73,95 \% \mathrm{CI}=1.30,5.71)$. No other variables were significantly associated with endocarditis in the bivariate analyses. Logistic regression was use to perform multivariable analyses, but no other variables were significantly associated with endocarditis. No variables were significantly associated with in-hospital mortality. CA-MRSA was associated with nearly three times the odds of in-hospital mortality, (OR = $2.93,95 \% \mathrm{CI}=0.78,10.96)$. We could not fully evaluate the associations between APACHE $\geq 11$ and receiving ART and mortality, because none of the patients who received ART died and none of the patients with APACHE less than 11 died.

\section{Discussion}

We present the largest cohort of HIV patients with CAMRSA bacteremia and endocarditis documented to date. These data suggest a high prevalence of CA-MRSA among HIV patients presenting with $S$. aureus bacteremia at our institution and that CA-MRSA was significantly associated with the development of endocarditis compared to non-CA-MRSA. Furthermore, although not significant, patients with CA-MRSA also appeared to be at increased risk of death compared to patients with other $S$. aureus bloodstream infections.

Table 3 Odds Ratios (ORs) and 95\% Confidence Intervals (Cls) for Associations of various Risk Factors for Endocarditis and In-hospital Mortality among HIV Patients with Staphylococcus aureus Bacteremia $(n=131)$

\begin{tabular}{lcc}
\hline & Endocarditis & In-hospital Mortality \\
\hline Characteristic & $\mathrm{OR}(95 \% \mathrm{Cl})$ & $\mathrm{OR}(95 \% \mathrm{Cl})$ \\
\hline CA-MRSA & $2.73(1.30,5.71)$ & $2.93(0.78,10.96)$ \\
\hline Age & $0.98(0.94,1.03)$ & $1.08(0.99,1.17)$ \\
\hline Male Sex & $0.46(0.22,0.94)$ & $0.35(0.10,1.33)$ \\
\hline Receiving ART & $0.67(0.31,1.42)$ & ${ }^{*}$ \\
\hline APACHE II $\geq \mathbf{1 1}$ & $1.71(0.85,3.42)$ & ${ }^{* *}$ \\
\hline CD4 <200 cells/mm $\mathbf{m m}^{\mathbf{3}}$ & $2.01(0.87,4.62)$ & $0.47(0.08,2.91)$ \\
\hline Hepatitis C & $1.23(0.60,2.50)$ & $0.57(0.16,2.08)$ \\
\hline Hypertension & $0.92(0.40,2.12)$ & $0.91(0.18,4.57)$ \\
\hline Intravenous Drug Use & $1.79(0.90,3.59)$ & $1.58(0.42,5.87)$ \\
\hline End-stage Renal Disease & $1.23(0.48,3.12)$ & $0.56(0.07,4.68)$ \\
\hline
\end{tabular}

Note: CA-MRSA: community-associated methicillin-resistant Staphylococcus aureus, ART: antiretroviral therapy, APACHE: Acute Physiology and Chronic Health Evaluation score

*Could not be calculated because no patients receiving ART died.

${ }^{*}$ Could not be calculated because no patients with APACHE $<11$ died. 
Kempker et al. presented a large cohort of CA-MRSA bacteremia cases from eight hospitals over 3 years in the Atlanta, GA metropolitan area.(10) They had 414 episodes of CA-MRSA bacteremia of which $63(16.2 \%)$ occurred in HIV positive patients and only 17 (4.1\%) were associated with endocarditis. They observed greater in-hospital mortality (17\%) compared to $8 \%$ in our study, however similar to the patients in our cohort, they observed more deep abscesses in their CA-MRSA group compared to the non-CA-MRSA group [10]. Wang et al. performed a study of adult patients with $S$. aureus bacteremia in Taiwan, however, only 3 (10\%) of their CA-MRSA bacteremia episodes had endocarditis, and none were HIV positive. On their univariate analysis, women appear to have a two-fold increase of dying with CA-MRSA bacteremia, a similar finding to our study [30]. Several other papers on CA-MRSA bacteremia have had very few cases of endocarditis most of which appear to be associated with deep abscesses and pulmonary disease [31-34]. Kreisel et al evaluated CAMRSA bacteremia and severe sepsis at 4 Veteran Affairs (VA) centers, which includes the Baltimore VA medical center and demonstrated that CA-MRSA was associated with more severe sepsis (adjusted relative risk 1.82, confidence intervals $1.16-2.87, \mathrm{p}=0.01$ ) [35]. They also noted that there was a greater propensity to ISU and African American patients having these severe infections, which is consistent with our population $[35,36]$.

Another major difference between our study and previously published work is the antibiotic susceptibility profile of our CA-MRSA strains compared to other studies with high levels of trimethoprim-sulfamethoxazole (TMP-STX) resistance, which was $32 \%$ of all isolates and $48 \%$ of the CA-MRSA isolates. This compares to ranges of $0-13 \%$ in other published studies [30,32-34]. TMP-STX resistance could have several possible explanations given the patient population examined; 1) As the majority of the patients had a history of intravenous drug usage, it is possible they had more abscesses in the past and had been treated with TMP-STX several times or 2) the majority of the patients had CD $4<200$ cells/ $\mathrm{mm}^{3}$ and were most likely taking TMP-STX for prevention of pneumocystis pneumonia. The second explanation appears more likely as our clindamycin resistance was similar to other studies [30,32-34].

Our data compare similarly to data published from Detroit, which also has high rates of CA-MRSA. CAMRSA was responsible for $35 \%$ of bloodstream infections in their series, but there were only $3 \%$ HIV infected patients in their cohort [37]. Lalani et al. during a multicenter clinical trial that the reported a prevalence of CA-MRSA was $12 \%$ among 230 S. aureus isolates and $31 \%$ among the 88 typed MRSA isolates in a multicenter clinical trial.(28) Incidence of endocarditis was $23 \%$.
However, in contrast to our study, the Lalani et al. study population had a low prevalence of HIV/AIDS of approximately $3 \%$ and thus a thorough comparison to the patients in our study is not possible. Gebo et al. assessed risk factors and outcomes of 58 cases of infective endocarditis among HIV-infected patients and identified intravenous drug use, low $\left(<50\right.$ cells $\left./ \mathrm{mm}^{3}\right)$ CD4 counts, and high (HIV RNA >100,000 copies/ML) viral load as independent risk factors for endocarditis. (3) Although $S$. aureus was the most prevalent organism (69\% of cases) in their study, only $28 \%$ of S. aureus isolates were MRSA, which also complicates comparison to our data, which focused on differences in risk factors and outcomes between CA-MRSA and non-CA-MRSA.

We observed relatively low mortality ( $8 \%)$ despite that greater than $20 \%$ of patients had a CD4 count of $<200$ cells $/ \mathrm{mm}^{3}$ and less than $30 \%$ were receiving ART. The low rate of ART use in our population with high ISU reflects the difficulty in obtaining compliance in this population. There have been several studies on the difficulties in getting the HIV infected ISU patients to establish and maintain antiretroviral usage in the city of Baltimore. It has been suggested that ISU infected patients with HIV who were not receiving ART tended to be active drug users without clinical disease [38]. It may explain why there was higher mortality in women in our study with the sex for illicit drug trade delaying the presentation for care [39].

Our results contrast previous studies, which observed mortality from $18 \%$ to $52 \%$ [3,5]. However, the associations between ISU, right-sided endocarditis and low relative mortality have been previously described, even among HIV patients [40]. Recall that more than $80 \%$ of our patients with endocarditis had right-sided disease only. Furthermore, as has been previously reported, the criteria used to measure mortality often vary in studies of infectious disease outcomes [41]. For example, the $52 \%$ mortality reported by Gebo et al. included all deaths within one year, some of which were likely not attributable to the endocarditis episode [3]. The low mortality in this study relative to the potential seriousness of the underlying infection, suggests that although CA-MRSA was significantly associated with endocarditis, this may be more related to risk associated with intravenous drug use and other outcomes such as mortality may still not be as severe as among other endocarditis patients $[42,43]$. Furthermore, other studies have suggested that HIV infection was not significantly associated with mortality among patients with infective endocarditis in which $65 \%$ were caused by S. aureus, $38 \%$ of patients were HIV-positive and $16 \%$ mortality was observed [6].

The retrospective nature of the study limited which data were able to be collected and the availability of $S$. 
aureus isolates. Furthermore, we used a molecular definition of USA300 MRSA to define CA-MRSA. While USA300 remains the predominant CA-MRSA, we likely underestimated the prevalence of CA-MRSA in this study. Lastly, given the high prevalence of CA-MRSA, ISU, and HIV in the study population and in Baltimore City in general, the generalizability of these data to other patient populations outside of urban, tertiary-care settings should be performed with caution.

\section{Conclusions}

In conclusion, CA-MRSA was significantly associated with an increased prevalence of endocarditis in this cohort of HIV patients with MRSA bacteremia. Despite that we observed lower mortality compared with other studies, these patients remain at considerably higher risk for the development of endocarditis and related mortality. In populations such as these, in which the prevalence of intravenous drug use and probability of endocarditis are both high, efforts must be made for early detection, which may improve treatment outcomes.

\section{Acknowledgements}

The authors would like to thank Eli N. Perencevich, MD, MS for his assistance with analysis and interpretation of the data.

Work Performed at the University of Maryland Medical Center, Baltimore, MD.

Funding Sources: National Institutes of Health Grants M01 RR16500, University of Maryland General Clinical Research Center, 1K01A1071015-03 (J. P.F.) and 1K12RR023250-04 (J.K.J.) and a grant from the Southern Medical Association (A.U.).

None of these funding bodies were involved in any preparation of the manuscript.

Disclosure of Previous Presentation of Data: These data were presented in part at the 46 Annual Interscience Conference on Antimicrobial Agents and Chemotherapy (ICAAC), San Francisco, CA (Presentation \#K-0779).

\section{Author details}

'Department of Pharmacy Practice, Oregon State University/Oregon Health and Sciences College of Pharmacy, Portland, OR, USA. ${ }^{2}$ Department of Pathology, University of Maryland School of Medicine, Baltimore, MD, USA. ${ }^{3}$ Department of Internal Medicine, University of lowa Carver College of Medicine, lowa City, IA, USA. ${ }^{4}$ Oro Valley Hospital, Oro Valley, AZ, USA. ${ }^{5}$ Department of Epidemiology and Public Health, University of Maryland School of Medicine, Baltimore, MD, USA. ${ }^{6}$ Food and Drug Administration, Silver Spring, MD, USA. ${ }^{7}$ Division of Infectious Diseases, Portland VA Medical Center and Oregon Health Science University, Portland, OR, USA.

\section{Authors' contributions}

$\mathrm{AU}$ and GF conceived the study, participated in the design and data collection and drafted the final manuscript. JF participated in study design, obtaining grant support and drafted the final manuscript. MLS and SMS participated in the statistical analysis and were involved in drafting the final manuscript. JKK and OCS performed the molecular testing on the clinical specimens and contributed in drafting the manuscript.

All authors read and approved the final manuscript.

\section{Competing interests}

In the past 5 years J.P.F. and M.L.S. have served as consults for Cubist Pharmaceuticals, Inc. Also, G.N.F. has received research funding and honoraria from Cubist Pharmaceuticals, Inc. and Pfizer Inc. M.L.S. has received research funding from Pfizer, Inc.
Received: 30 March 2011 Accepted: 31 October 2011

Published: 31 October 2011

\section{References}

1. Cosgrove SE, Sakoulas G, Perencevich EN, Schwaber MJ, Karchmer AW, Carmeli Y: Comparison of mortality associated with methicillin-resistant and methicillin-susceptible Staphylococcus aureus bacteremia: a metaanalysis. Clin Infect Dis 2003, 36:53-59.

2. Cosgrove SE: The relationship between antimicrobial resistance and patient outcomes: mortality, length of hospital stay, and health care costs. Clin Infect Dis 2006, 42(Suppl 2):S82-S89.

3. Gebo KA, Burkey MD, Lucas GM, Moore RD, Wilson LE: Incidence of, risk factors for, clinical presentation, and 1-year outcomes of infective endocarditis in an urban HIV cohort. J Acquir Immune Defic Syndr 2006, 43:426-432.

4. Popovich KJ, Weinstein RA, Hota B: Are community-associated methicillinresistant Staphylococcus aureus (MRSA) strains replacing traditional nosocomial MRSA strains? Clin Infect Dis 2008, 46:787-794.

5. Cicalini S, Forcina G, De Rosa FG: Infective endocarditis in patients with human immunodeficiency virus infection. J Infect 2001, 42:267-271.

6. De Rosa FG, Cicalini S, Canta F, Audagnotto S, Cecchi E, Di PG: Infective endocarditis in intravenous drug users from Italy: the increasing importance in HIV-infected patients. Infection 2007, 35:154-160.

7. Fridkin SK, Hageman JC, Morrison M, Sanza LT, Como-Sabetti K, Jernigan JA, et al: Methicillin-resistant Staphylococcus aureus disease in three communities. N Engl J Med 2005, 352:1436-1444.

8. Pan ES, Diep BA, Carleton HA, Charlebois ED, Sensabaugh GF, Haller BL, et al: Increasing prevalence of methicillin-resistant Staphylococcus aureus infection in California jails. Clin Infect Dis 2003, 37:1384-1388.

9. Burkey MD, Wilson LE, Moore RD, Lucas GM, Francis J, Gebo KA: The incidence of and risk factors for MRSA bacteraemia in an HIV-infected cohort in the HAART era. HIV Med 2008, 9:858-862.

10. Kempker RR, Farley MM, Ladson JL, Satola S, Ray SM: Association of methicillin-resistant Staphylococcus aureus (MRSA) USA300 genotype with mortality in MRSA Bacteremia. J Infect 2010, 61:372-381.

11. AIDS Administration Maryland Department of Health and Mental Hygiene: The Maryland 2009 HIV/AIDS annual report. 2009, 2008.

12. Klevens RM, Morrison MA, Nadle J, Petit S, Gershman K, Ray S, et al: Invasive methicillin-resistant Staphylococcus aureus infections in the United States. JAMA 2007, 298:1763-1771.

13. Weber SG, Miller RR, Perencevich EN, Tolentino J, Meltzer D, Pitrak D, et al: Prevalence of antimicrobial-resistant bacteria isolated from older versus younger hospitalized adults: results of a two-centre study. J Antimicrob Chemother 2009, 64:1291-1298.

14. McGregor JC, Weekes E, Forrest GN, Standiford HC, Perencevich EN, Furuno JP, et al: Impact of a computerized clinical decision support system on reducing inappropriate antimicrobial use: a randomized controlled trial. J Am Med Inform Assoc 2006, 13:378-384.

15. Wright MO, Perencevich EN, Novak C, Hebden JN, Standiford HC, Harris AD: Preliminary assessment of an automated surveillance system for infection control. Infect Control Hosp Epidemiol 2004, 25:325-332.

16. Furuno JP, McGregor JC, Harris AD, Johnson JA, Johnson JK, Langenberg $P$, et al: Identifying groups at high risk for carriage of antibiotic-resistant bacteria. Arch Intern Med 2006, 166:580-585.

17. Furuno JP, Harris $\mathrm{AD}$, Wright $\mathrm{MO}$, Hartley DM, McGregor $\mathrm{JC}$, Gaff $\mathrm{HD}$, et al: Value of performing active surveillance cultures on intensive care unit discharge for detection of methicillin-resistant Staphylococcus aureus. Infect Control Hosp Epidemiol 2007, 28:666-670.

18. Schweizer ML, Furuno JP, Harris AD, McGregor JC, Thom KA, Johnson JK et al: Clinical utility of infection control documentation of prior methicillin-resistant Staphylococcus aureus colonization or infection for optimization of empirical antibiotic therapy. Infect Control Hosp Epidemiol 2008, 29:972-974.

19. KDOQI Clinical Practice Guidelines For Chronic Kidney Disease: Evaluation, Classification and Stratification. National Kidney Foundation 2002.

20. Li JS, Sexton DJ, Mick N, Nettles R, Fowler VG Jr, Ryan T, et al: Proposed modifications to the Duke criteria for the diagnosis of infective endocarditis. Clin Infect Dis 2000, 30:633-638. 
21. Clinical and Laboratory Standards Institute: Performance Standards for Antimicrobial Susceptibility Testing; Approved Standard Document M100-S17. Wayne, Pa; 2007.

22. Furuno JP, Perencevich EN, Johnson JA, Wright MO, McGregor JC, Morris JG $\mathrm{Jr}$, et al: Methicillin-resistant Staphylococcus aureus and vancomycinresistant Enterococci co-colonization. Emerg Infect Dis 2005, 11:1539-1544.

23. Harmsen D, Claus H, Witte W, Rothganger J, Claus H, Turnwald D, et al: Typing of methicillin-resistant Staphylococcus aureus in a university hospital setting by using novel software for spa repeat determination and database management. J Clin Microbiol 2003, 41:5442-5448.

24. Shopsin B, Gomez M, Waddington M, Riehman M, Kreiswirth BN: Use of coagulase gene (coa) repeat region nucleotide sequences for typing of methicillin-resistant Staphylococcus aureus strains. J Clin Microbiol 2000, 38:3453-3456

25. Diep BA, Gill SR, Chang RF, Phan TH, Chen JH, Davidson MG, et al: Complete genome sequence of USA300, an epidemic clone of community-acquired meticillin-resistant Staphylococcus aureus. Lancet 2006, 367:731-739

26. Lina G, Piemont Y, Godail-Gamot F, Bes M, Peter MO, Gauduchon V, et al: Involvement of Panton-Valentine leukocidin-producing Staphylococcus aureus in primary skin infections and pneumonia. Clin Infect Dis 1999, 29:1128-1132.

27. Johnson JK, Khoie T, Shurland S, Kreisel K, Stine OC, Roghmann MC: Skin and soft tissue infections caused by methicillin-resistant Staphylococcus aureus USA300 clone. Emerg Infect Dis 2007, 13:1195-1200

28. McDougal LK, Steward CD, Killgore GE, Chaitram JM, McAllister SK, Tenover FC: Pulsed-field gel electrophoresis typing of oxacillin-resistant Staphylococcus aureus isolates from the United States: establishing a national database. J Clin Microbiol 2003, 41:5113-5120.

29. Lalani T, Federspiel JJ, Boucher HW, Rude TH, Bae IG, Rybak MJ, et al: Associations between the Genotype of Staphylococcus aureus Bloodstream Isolates and the Clinical Characteristics and Outcomes of Bacteremic Patients. J Clin Microbiol 2008.

30. Wang JL, Chen SY, Wang JT, Wu GH, Chiang WC, Hsueh PR, et al: Comparison of both clinical features and mortality risk associated with bacteremia due to community-acquired methicillin-resistant Staphylococcus aureus and methicillin-susceptible S. aureus. Clin Infect Dis 2008, 46:799-806.

31. Beeston CJ, Gupta R, Chadwick PR, Young RJ: Methicillin-resistant Staphylococcus aureus bacteraemia and mortality in a teaching hospital. Eur J Clin Microbiol Infect Dis 2009, 28:585-590.

32. Chen SY, Wang JT, Chen TH, Lai MS, Chie WC, Chien KL, et al: Impact of traditional hospital strain of methicillin-resistant Staphylococcus aureus (MRSA) and community strain of MRSA on mortality in patients with community-onset S aureus bacteremia. Medicine (Baltimore) 2010, 89:285-294.

33. Robinson JO, Pearson JC, Christiansen KJ, Coombs GW, Murray RJ: Community-associated versus healthcare-associated methicillin-resistant Staphylococcus aureus bacteraemia: a 10-year retrospective review. Eur $J$ Clin Microbiol Infect Dis 2009, 28:353-361.

34. Wang JT, Wang JL, Fang CT, Chie WC, Lai MS, Lauderdale TL, et al: Risk factors for mortality of nosocomial methicillin-resistant Staphylococcus aureus (MRSA) bloodstream infection: with investigation of the potential role of community-associated MRSA strains. J Infect 2010, 61:449-457.

35. Kreisel KM, Stine OC, Johnson JK, Perencevich EN, Shardell MD, Lesse AJ, et al: USA300 methicillin-resistant Staphylococcus aureus bacteremia and the risk of severe sepsis: is USA300 methicillin-resistant Staphylococcus aureus associated with more severe infections? Diagn Microbiol Infect Dis 2011, 70:285-290.

36. Kreisel KM, Johnson JK, Stine OC, Shardell MD, Perencevich EN, Lesse AJ, et al: Illicit drug use and risk for USA300 methicillin-resistant Staphylococcus aureus infections with bacteremia. Emerg Infect Dis 2010, 16:1419-1427.

37. Chua T, Moore CL, Perri MB, Donabedian SM, Masch W, Vager D, et al: Molecular epidemiology of methicillin-resistant Staphylococcus aureus bloodstream isolates in urban Detroit. J Clin Microbiol 2008, 46:2345-2352.

38. Celentano DD, Vlahov D, Cohn S, Shadle VM, Obasanjo O, Moore RD: Selfreported antiretroviral therapy in injection drug users. JAMA 1998, 280:544-546

39. Mehta SH, Kirk GD, Astemborski J, Galai N, Celentano DD: Temporal trends in highly active antiretroviral therapy initiation among injection drug users in Baltimore, Maryland, 1996-2008. Clin Infect Dis 2010, 50:1664-1671.

40. Moss R, Munt B: Injection drug use and right sided endocarditis. Heart 2003, 89:577-581.

41. McGregor JC, Rich SE, Harris AD, Perencevich EN, Osih R, Lodise TP Jr, et al: A systematic review of the methods used to assess the association between appropriate antibiotic therapy and mortality in bacteremic patients. Clin Infect Dis 2007, 45:329-337.

42. Abraham J, Mansour C, Veledar E, Khan B, Lerakis S: Staphylococcus aureus bacteremia and endocarditis: the Grady Memorial Hospital experience with methicillin-sensitive $S$ aureus and methicillin-resistant $S$ aureus bacteremia. Am Heart J 2004, 147:536-539.

43. Ellington MJ, Hope R, Ganner M, Ganner M, East C, Brick G, et al: Is PantonValentine leucocidin associated with the pathogenesis of

Staphylococcus aureus bacteraemia in the UK? J Antimicrob Chemother 2007, 60:402-405.

Pre-publication history

The pre-publication history for this paper can be accessed here: http://www.biomedcentral.com/1471-2334/11/298/prepub

doi:10.1186/1471-2334-11-298

Cite this article as: Furuno et al:: Community-associated Methicillinresistant Staphylococcus aureus Bacteremia and Endocarditis among HIV Patients: A cohort study. BMC Infectious Diseases 2011 11:298.

\section{Submit your next manuscript to BioMed Central and take full advantage of:}

- Convenient online submission

- Thorough peer review

- No space constraints or color figure charges

- Immediate publication on acceptance

- Inclusion in PubMed, CAS, Scopus and Google Scholar

- Research which is freely available for redistribution

Submit your manuscript at www.biomedcentral.com/submit
Biomed Central 